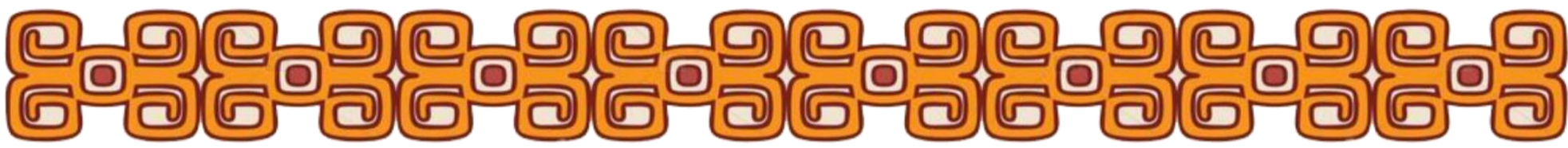

\title{
PARA UMA FENOMENOLOGIA DA ALMA FEMININA: O PROTAGONISMO E A VISIBILIDADE DA MULHER
}

\author{
Adson Manoel Bulhões da Silva \\ Iraildes Caldas Torres
}

RESUMO

Este trabalho busca esclarecer uma doutrina de formação especificamente feminina, no que diz respeito à vocação natural da mulher, seu protagonismo social na Amazônia, destacando a formação da mulher, perante o seu ser natural e social e envolvendo questões feministas, que, por sua vez, insiste em entender a mulher apenas como um ser predominantemente social. Contudo, Stein (1999) trata da relação da alma feminina com o mundo moderno, no que se refere à própria concepção de entendimento do ser feminino e da pessoalidade da mulher. Mostra que a mulher pode ganhar espaço no mercado e na sociedade, sendo profissional competente e respeitada, sem necessariamente ter que se descaracterizar. A abordagem steiniana do assunto, antes de ter a pretensão de impor uma verdade, busca dialogar séria e abertamente com outros posicionamentos a respeito do assunto.

\section{PALAVRAS-CHAVE}

Alma. Feminina. Protagonismo. Amazônia.

\section{INTRODUÇÃO}

O presente estudo tem por objetivo fazer uma análise antropológica, filosófica e social do feminino em particular, a partir das investigações realizadas por Edith Stein frente à realidade das mulheres. Ao longo da pesquisa, busca-se, também, examinar a relação do ser humano com a dimensão religiosa e social. Em um olhar desprovidos de preconceitos, verifica-se que existe uma profunda conexão entre a experiência religiosa e o teor feminino elucidados na obra de Edith Stein, A Mulher: sua Missão segundo a Natureza e a Graça, que possui o intuito de mostrar que a mulher e o homem são seres naturalmente diferentes no corpo, na alma, assim como em sua força e sensibilidade.

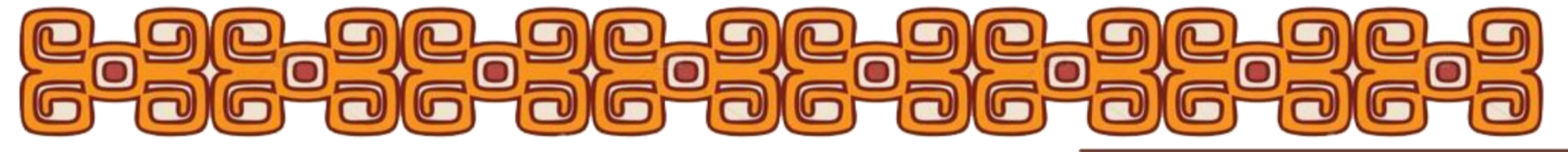




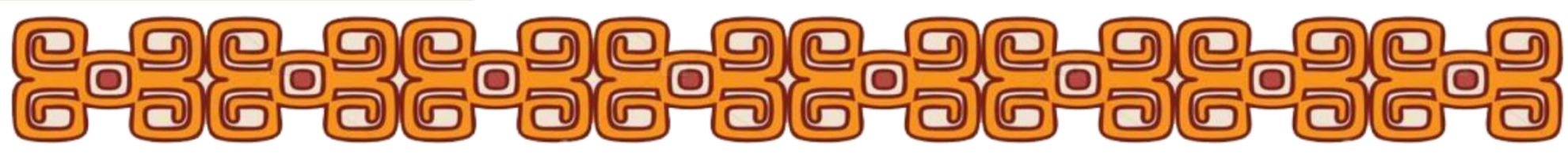

Nessa perspectiva, as relações de gênero se põem neste cenário do contemporâneo, com significativo teor conceptual para iluminar o escuro espraiado na textura lacunar das ausências $^{1}$, da invisibilidade e do preconceito com relação às mulheres. Diante disso, a filosófica de Edith Stein torna-se decisiva para a conexão com uma memória narrativa de solidariedade de tantas biografias esquecidas de mulheres esquecidas na nossa história.

Assim, as relações de gênero também ganham força com os aportes do pensamento feminino que não somente produzirá modificações e alterações nos problemas, mas também dará respostas filosóficas, antropológicas, epistemológicas e éticas.

É neste cenário que o estudo da subjetividade a partir visibilidade da alma feminina e conceitos relacionados como: a pessoalidade e alteridade, possuem um campo epistêmico das relações de gênero que engendra um significado importante à esta temática. Especialmente porque, no caso deste estudo, há um entrelaçamento com o imaginário feminino amazônico e a realidade da mulher amazônida. Dessa forma, a subjetividade aqui estudada está circunscrita nos domínios desse conjunto de entendimentos que se entrelaçam ao ser, através da alma que se materializam em atos que se dão no âmbito do real ou do imaginário, ambos vividos e experimentados.

Por conta disso, este estudo assume também o objetivo de desvelar os sentidos e significados, sua importância e influência, buscando compreendê-la no âmbito da filosofia, história, natural e social. O estudo atende a uma perspectiva teórica de cunho investigativo tendo por base a dialógica, sugerida por Edith Stein, que nos permitiu tecer uma rede de conversa com outros saberes no contexto amazônico em particular.

Diante das elucidações anteriores, torna-se salutar o desabrochar do pensamento de Stein para a análise cientifica no horizonte perspectivo enfatizado por Michel Maffesoli, ao propor que é preciso demarcar o caminho da pós-modernidade, da mesma maneira como fizera Descartes ao delimitar o da modernidade. O pensamento desse último e de vários outros teóricos, defensores da razão abstrata, já não consegue prevalecer na contemporaneidade, que é o momento histórico em que a aparência, o senso comum ou a

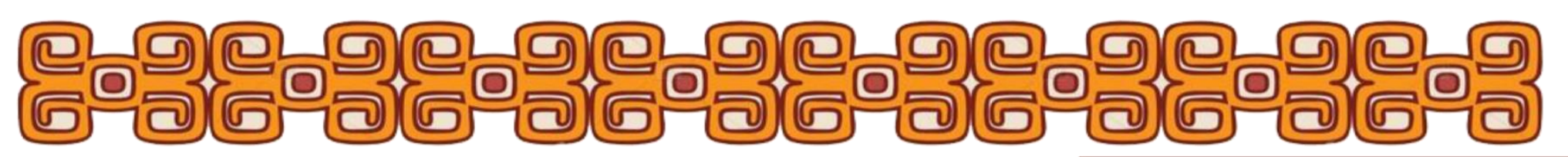

\footnotetext{
${ }^{1}$ Ver a este propósito Boaventura Santos. A crítica da razão indolente: contra o desperdício da experiência (2006).
} 


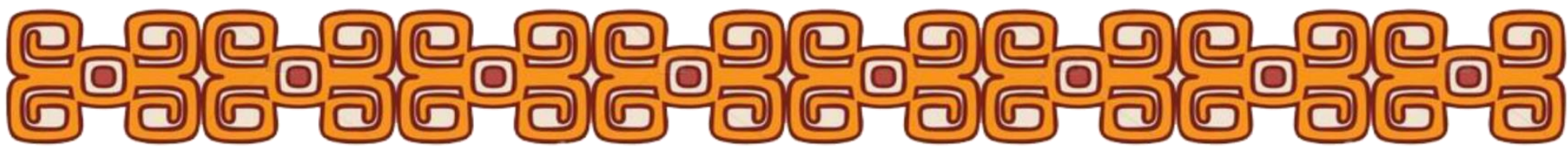

Nessa perspectiva Margareth Rago (1995), deixou em evidência sua crítica severa aos estudos que enfatizavam as análises das identidades prontas e aos que marginalizavam as construções simbólicas e culturais dos agentes em suas experiências de vida. No interior de sua proposta da desnaturalização dos sujeitos e dos objetos históricos e da concepção dos discursos como práticas instituintes de realidades, tem-se a necessidade de entender os indivíduos em suas facetas de produtores e produtos das construções sociais e culturais.

O conceito de gênero, como se vê, abre um feixe de possibilidades de análises interseccionais e transversais no campo das ciências humanas. Torres (2005), em complementariedade ao conceito de gênero acrescenta mais três elementos, considerando que este conceito também estabelece intersecção com as noções de geração, região e nação.

Há segmentos etários de mulheres e até de homens que enfrentam mais preconceitos do que outros, tais como a terceira idade, do mesmo modo que a região amazônica recebe uma carga mais elevada de preconceito de gênero em virtude de sua população possuir o matiz étnico-indígena. Na compreensão de (Torres, 2015, p. 19), "é preciso quebrar o silêncio de gênero na floresta amazônica...". Nesse prisma, é assim que a nação brasileira, em particular a Amazônia, é vista pelo imaginário mundial como o lugar de mulheres lascivas, sambistas e desnudas.

Diante desse horizonte perspectivo, busca-se um aprofundamento nos estudos de gênero à luz do pensamento de Edith Stein na compreensão da fenomenologia da alma humana em particular a alma feminina e suas peculiaridades frente ao mundo da vida.

\section{A ALMA FEMININA}

Esclarecido por meio das ideias contidas na obra: A Mulher: Sua Missão Segundo a Natureza e a Graça, Stein discute um problema a ser enfrentado: por causa de sua alma o ser feminino é dessemelhante por que sua alma é diferente. "A Alma Feminina só poderá amadurecer para o ser que lhe é adequado, se as suas forças receberem a devida formação" (Stein, 1999, p. 116). Dessa forma, a alma espiritual é o princípio vital do corpo material, não podendo ser confundida ou identificada com corpo e espírito.

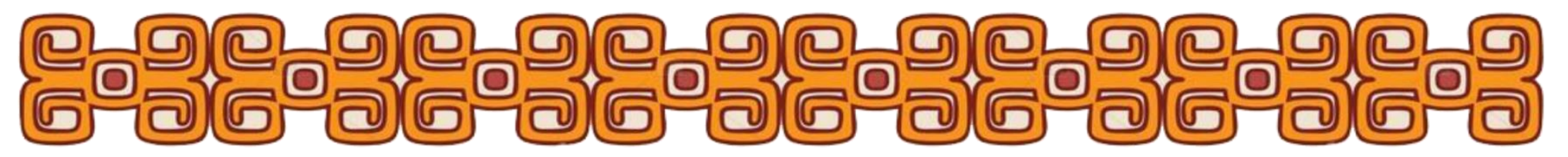




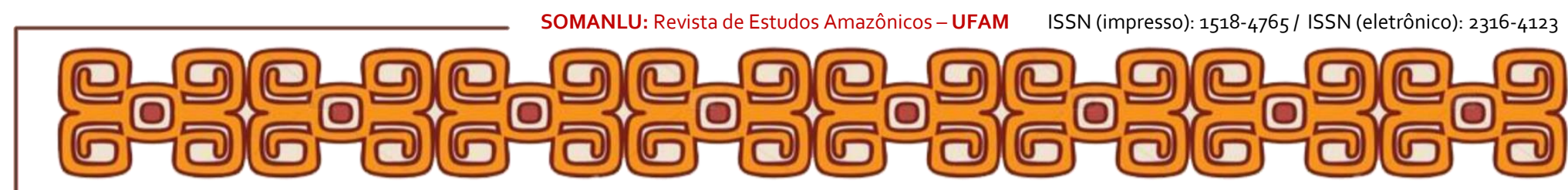

A alma humana não é algo pronto e estático. A alma humana é "una", pois há em seu cerne uma subjacente força divina. A alma feminina como ser específico atribui um fim à mulher, uma vocação em que todo o seu ser está em função desse mesmo fim. Com isso, parece claro que a mulher tem uma predisposição natural à maternidade e a ser companheira.

Ela naturalmente apresenta uma sensibilidade e compreensão para com o outro conforme nos atesta Edith Stein: "Em todas, encontro uma índole comum: o desejo de dar e de receber amor, e com isso, a aspiração de serem tiradas da estreiteza de sua existência real atual para serem guindadas a um ser e agir mais elevado" (Stein, 1999, p.102). Até mesmo a ligação da alma com o corpo se dá de forma diferenciada.

Nessa diferenciação que está estreitamente ligada à vocação materna da mulher, Edith Stein acentua uma dupla possibilidade de vivenciá-la: uma de maneira espiritual e outra de maneira biológica. É o caso, por exemplo, de uma mulher que, profundamente tocada pela sua missão específica, dedica no celibato sua vida em favor de outros. Poderia tal mulher chegar à plenitude do ser feminino, já que a maternidade faz parte da essência feminina? Responderia Edith Stein: "Com toda certeza!". Pois, da mesma forma que uma mulher seja mãe biologicamente, ainda assim, é preciso todo um trabalho interior de maturação humano-espiritual para que ela chegue ao escopo de sua plena maturidade.

Assim, a alma feminina está mais presente em todas as partes do corpo, de modo que se sente mais atingida em seu íntimo por tudo que the acontece, enquanto para o homem o corpo assume mais o caráter de instrumento que está ao seu controle, o que provoca certo afastamento. Tal fato incontestável é o recurso dado pela natureza feminina para executar sua missão como mulher. Porém, uma vez mal compreendido gera uma cultura do sexo frágil, e o que deveria ser visto como força é deturpada pela falta de formação.

Edith Stein discorre que a presença do universo arraigado pelo ser feminino é algo raro, ainda quando se trata de demandas referentes á própria mulher. Abordagens específicas sobre a natureza da mulher são pouco teorizadas. Apresenta-se assim, a necessidade de designar novos parâmetros para um pensar que tenha uma função específica de tratar do ser feminino.

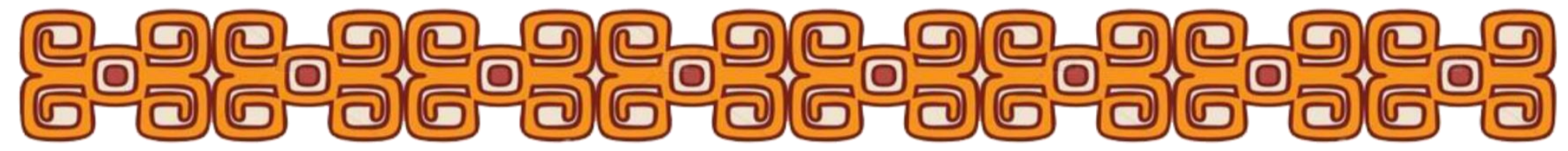




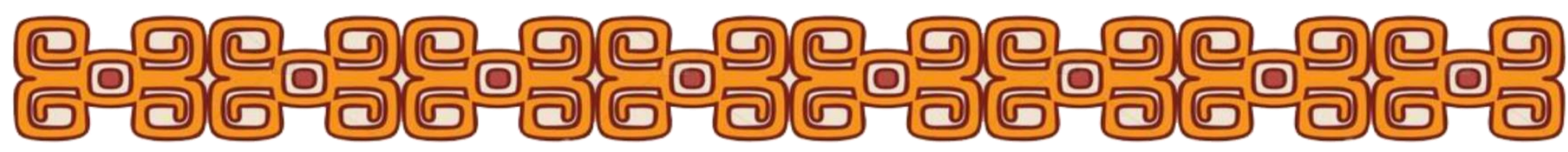

de humanização, de fazer com que as coisas ao seu redor ganhem novas 'cores', as 'cores' da humanização. Por isso, "a mulher que não é nem esposa nem mãe, precisa comprovar essa maternidade espiritual em suas atitudes e ações" (Stein, 1999, p.224).

Para vigorar esta concepção, Edith Stein ressalta que: "o corpo é a parte visível e material do ser humano, parte esta, onde ocorrem os fenômenos físicos, o espírito é a dimensão transcendente, onde o homem relaciona-se com o seu criador", isto é, a dimensão vertical, onde o ser humano ultrapassa os fenômenos físicos e o mundo material. Já a alma é o vínculo que une o corpo e o espírito, participando tanto da vida sensível quanto da vida transcendente (espiritual).

Nas pontuações de Stein, entende-se que a pessoa implica em espiritualidade. O ser humano enquanto pessoa é ser espiritual, cujo espiríto tem algo peculiar: uma interioridade, um centro, a partir do qual se possui plenamente. Isto está em si mesmo e por ele é capaz de si mesmo. O entrar e sair de si mesmo são dois movimentos essenciais da pessoa.

Sendo a mulher, o único ser da humanidade capaz de gerar e nutrir no interior de seu corpo outro ser, ela é também, justamente por essa capacidade natural, mais afetiva e cuidadosa com o outro do que o homem. Na melhor das hipóteses, a mãe tem com sua "cria" uma relação diferente daquela cultivada pelo pai. Daí a propensão natural da mulher a estar atenta aos problemas alheios. Assim, a empatia natural da mulher se manifesta por meio da essência genitora de seu Ser, sendo na relação com o outro humano ou com o meio natural.

Sobre o entendimento de meio natural, Merleau-Ponty (2006), pontua que a natureza é um objeto enigmático, denominado pelo pensador como quiasma ${ }^{2}$, um objeto que não é inteiramente objeto; ela não está inteiramente diante de nós. É o nosso solo, não é aquilo que está diante, mas o que nos sustenta. Diante disso, Stein vigora o pensamento de Ponty, já que floresce a ideia que a natureza do Ser não se determina pelo corpo (físico).

Nessa perspectiva ontológica, os escritos de Stein elucidam que a história da sociedade encontra seu sentido no pensamento que parte da natureza para encontrar um porto seguro na própria essência do Ser feminino.

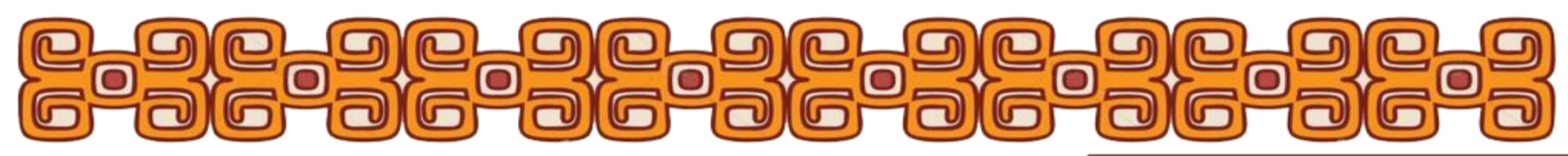

\footnotetext{
${ }^{2}$ Merleau-Ponty na noção de quiasma, compreendida como uma lógica de inerência e entrelaçamento entre os fenômenos e realidades.
} 


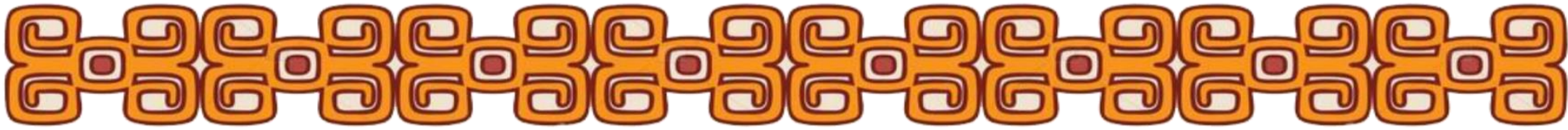

\section{O FEMININO E O MASCULINO DA ALMA: UMA FENOMENOLOGIA DUAL}

Embasada na fenomenologia e no estudo aristotélico-tomista, Edith Stein destaca que, mesmo sendo uma só a natureza humana, há diferenciações que se fazem notar entre homem e mulher, enquanto ser. Em ambos os casos acontece um fenômeno chamado de individuação, "princípio intrínseco às coisas, pelo qual são individuais" e que se deve procurar na matéria. Por isso, somente no mundo material podem existir indivíduos da mesma espécie (Stein, 1999, p.383).

É neste contexto que a diferença entre o feminino e o masculino é abordada ao lado da unidade do ser humano: de fato, homem e mulher são seres humanos. É nisso consiste sua igualdade, mas são diferentes também no sentido de que não é só o corpo ou não são só as funções fisiológicas que são diferentes. A vida toda no corpo é diferente, a relação entre a alma e o corpo é diferente e, no âmbito da alma, difere a relação entre o espírito e a sensitividade bem como a relação entre as diversas forças espirituais.

Nos estudos realizados sobre a mulher por Edith Stein, é salientada uma diferença ontológica que se encontra nas profundezas da estrutura da pessoa humana. A essência feminina, a que se refere à maternidade espiritual ${ }^{3}$, que é definida como um projeto aberto para a criação das mulheres, mesmo ela decidindo se deve ou não ter filhos.

A forma feminina e masculina não se manifesta só no ritmo constitutivo dos indivíduos, mas investe toda a estrutura de corpo, alma e espírito. Portanto, a diferença entre homem e mulher deve ser entendida como algo que atravessa toda a estrutura do ser humano, como tal pela diferenciação sexual. "Em cada indivíduo, encontramos o elemento masculino e feminino, sendo que apenas um deles predomina, precisamos então das duas espécies para desenvolver a espécie humana." Assim, Edith Stein indica brevemente no que consistem os momentos fundamentais da distinção entre a espécie masculina e espécie feminina: "A espécie feminina corresponde à unidade e à integridade de toda a personalidade psicofísica, o desenvolvimento harmonioso das forças; a espécie masculina

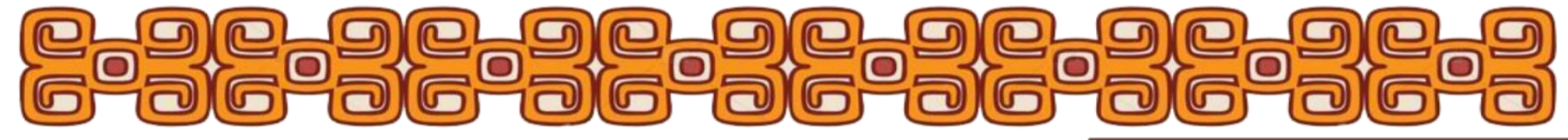

\footnotetext{
${ }^{3}$ Por maternidade espiritual Edith Stein entende que ela se mostra de múltiplas formas, por exemplo, segundo o carisma e as regras dos diversos Institutos de caráter apostólico, ela poderá exprimir-se como solicitude pelos homens, especialmente pelos mais necessitados: os doentes, os deficientes físicos, os abandonados, os órfãos, os idosos, as crianças, a juventude, os encarcerados, e, em geral, os marginalizados.
} 


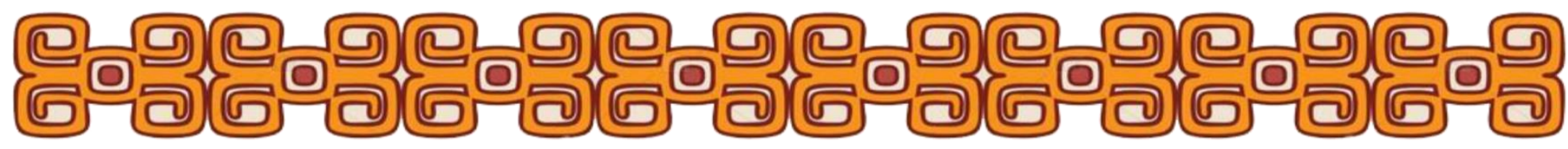

se destaca pela potencialização máxima de forças isoladas" (Stein, 1999, p 187-206).

Para compreender a diferença entre homem e mulher, em Stein, faz-se necessário, primeiramente, entender as naturezas feminina e masculina, que se completam em todos os âmbitos da pessoalidade humana. Ou seja, a capacidade intrínseca do ser humano de reunir em si uma diversidade-totalidade que, apesar de una, também é trina, isto é: corpo, alma e espirito.

É nesse ponto que se constata uma ligação entre filosofia e teologia: a diferenciação da espécie proposta pela filosofia responde à finalidade dos sexos assim como é apresentada pela teologia. É sobre essa diferença que a autora se fundamenta para indicar o destino da mulher e do homem, para aprofundar o significado do feminino em relação ao masculino e, consequentemente, para abordar a questão da relação entre os dois.

Edith Stein apresenta uma visão geral da fenomenologia e de sua relação com a complexidade do ser humano numa perspectiva de um pensamento filosófico, cujo estudo está centrado na análise transcendental. Dessa forma, considerando que vivência, essência, percepção, reflexão, lógica e sentido das coisas são aspectos interligados na subjetividade do mundo interior da pessoa.

Stein ressalta em seus escritos que a maioria dos autores cometeram graves equívocos sobre a verdadeira natureza da alma feminina, principalmente aqueles que sustentavam que mulher não tinha capacidades para exercer atividades na política ou meio profissional, classificando-as com habilidades relacionadas somente para atividades como no lar, mãe, esposa, etc.

Stein assinala em seus escritos que os direitos alcançados pelas mulheres em diversos âmbitos são salutares e positivos, porém devem ser feitas sem nunca perder de vista que o homem e a mulher são diferentes no corpo e na alma. Homem e mulher são diferentes, mas não desiguais, e querer além da igualdade social é ir contra sua natureza física, psíquica e espiritual.

A dignidade da mulher, pois, repousa em sua diferença ${ }^{4}$ com o homem, e não sobre sua desigualdade. Que a mulher tenha os mesmos direitos e os mesmos deveres enquanto

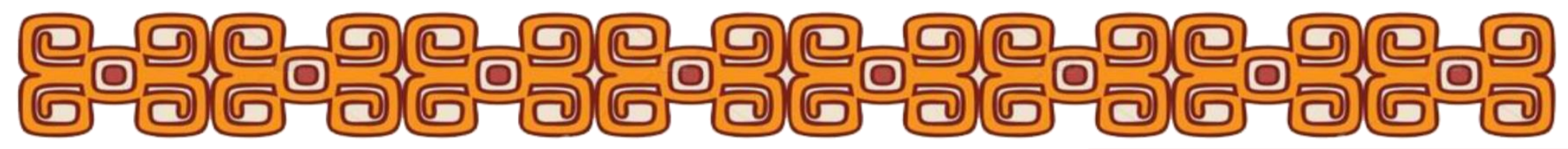

\footnotetext{
${ }^{4} \mathrm{O}$ que tem certa paridade, isto é, possui características afins, como por exemplo, a espécie, porém não nível de igualdade (exemplo: homem e mulher).
} 


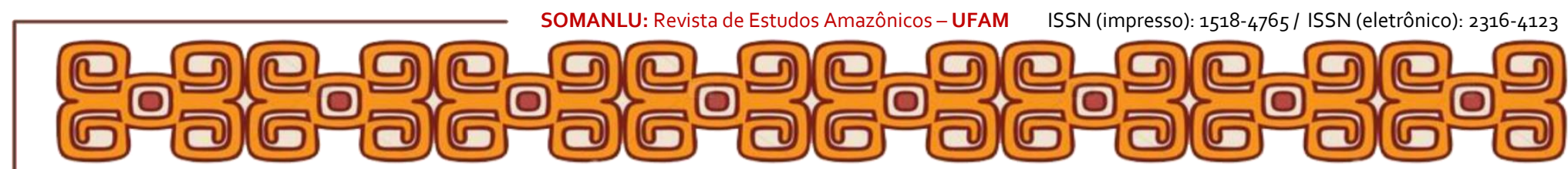

\section{O PROTAGONISMO HISTÓRICO-CULTURAL DA MULHER E O IMAGINÁRIO FEMININO NA AMAZÔNIA}

Historicamente a mulher vem lutando para galgar espaços sociais, pois como afirma (Perrot, 1992,p.75), "da História, muitas vezes a mulher é excluída". Muitas foram e continuam sendo as lutas das mulheres para tornarem-se visibilizadas na sociedade. Estudos sobre a mulher vêm sendo desenvolvido, mas ainda há muitas lacunas a serem preenchidas. Como é o caso do estudo acerca do protagonismo das mulheres amazônidas. Essa atuação de protagonismo feminino sugere um estudo acerca da relação de gênero na Amazônia. Pois como discorre (Torres, 2015, p.19), "é preciso quebrar o silêncio de gênero na floresta amazônica...".

$\mathrm{Na}$ perspectiva antropológica, destaca-se o próprio nome "Amazônia". Nome protagonizado por meio da história das mulheres icamiabas ${ }^{5}$, vistas como as lendárias amazonas pelo grupo de navegadores aventureiros espanhóis liderados pelo capitão Francisco de Orellana, que remeteu do Peru pelo Rio Amazonas em rumo ao Oceano Atlântico no século XVI.

Diante dos escritos, a suposta batalha travada por aquelas mulheres guerreiras contra os forasteiros espanhóis foi registrada com um misto de admiração e perplexidade, além de uma boa dose do que se poderia chamar de realismo fantástico, por frei Gaspar de Carvajal, o cronista oficial da expedição castelhana.

A figura da mulher esteve sempre presente no interior cultura, representando funções bem definidos e que procuram transmitir toda a força, protagonismo e também delicadeza que esta contém tanto no meio social como também nas representações simbólicas e na cultura imaterial tais como mitos e lendas.

Na mitologia grega o termo Theasofia, o significado de Thea/Tea é 'deusa', e Sofia/Sophia significa Sabedoria ou Saber. Assim, o arquétipo do princípio feminino Essencial: O Grande Feminino é a Sabedoria da Deusa, ou sabedoria do princípio divino

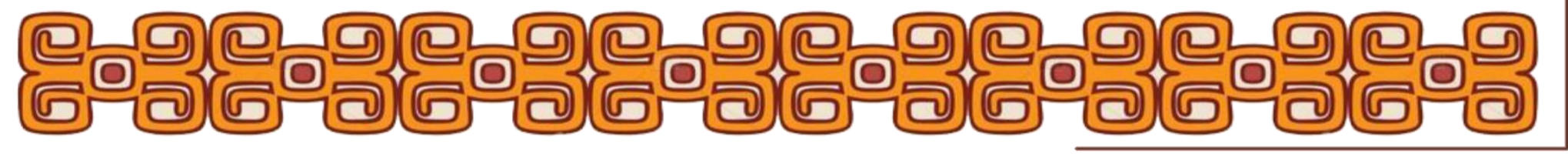

${ }^{5}$ Icamiabas' ou iacamiabas (significando "peito partido") é a designação genérica dada a índias que teriam formado uma tribo de mulheres guerreira que não aceitavam a presença masculina. 


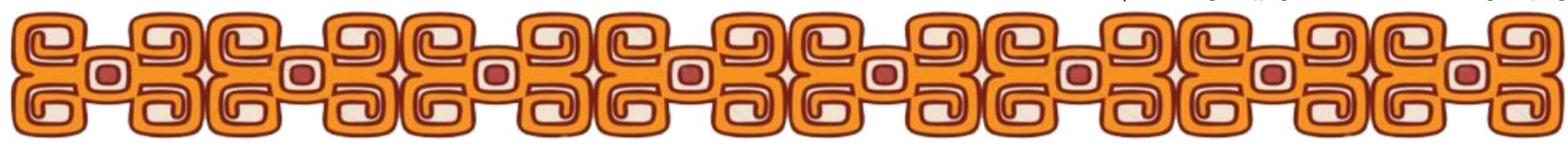

feminino. A sabedoria sobre o caminho do despertar do poder Superior, ou seja, o lado ou o polo feminino do divino, do sagrado, Absoluto. São os saberes e práticas da verdadeira sabedoria e espiritualidade feminina.

Assim, Theasofia é o nome em grego da Sabedoria iniciática Feminina, éa sabedoria das grandes sacerdotisas, xamas, curadoras e 'senhoras' dos círculos de mulheres em todo o mundo, porém ocultados pelas tendências e necessidades mais paternalistas sobre essência do despertar do poder e consciência plena feminina ou do feminino transcendente.

No âmbito da psicanálise Jung discorreu sobre a salutar figura feminina, trazendo Arquétipo mãe. Em seu itinerário intelectual buscou enfatizar o arquétipo da mãe como forma de mãe pessoal, avó, madrasta, sogra, enfermeira, governanta. Sendo que ele pode ser cumprido em mães figurativas, como Maria Mãe de Deus, ou a mãe que se torna uma donzela novamente no mito de Deméter e Kore.

Outros símbolos incluem a Igreja Matriz, país, a Terra, a floresta, o mar, um jardim, um campo arado, uma mola ou bem. O aspecto positivo do arquétipo mãe é o amor maternal e calor, tão celebrado na arte e na poesia, o que é dado a nossa primeira identidade no mundo. No entanto, ele pode ter significado negativo - a mãe amorosa ou a terrível mãe ou deusa do destino. Jung considerou a mãe o arquétipo mais importante, porque parecia conter uma dualidade de sentido.

Nesse contexto, torna-se necessário a reflexão sobre o posicionamento de Edith Stein sobre a natureza genuína e essência da mulher, a forma feminina de abordagem das questões relacionadas com o "mundo-da-vida" na "comunidade" e em seus desdobramentos históricos, haja vista que a forma feminina está ligada a natureza, a conexão do ser humano com o universo, sendo que esta conexão não é espírito, nem matéria, mas sim um elemento, como o ar, a terra, o fogo e água, que dá origem a tudo.

Nessa perspectiva, (Bachelard,1993, p.27) denomina de "fenomenologia da imaginação" ou "fenomenologia da alma", e ao mencioná-la, já discorre também o que para ele constitui o fenômeno a ser estudado: a imagem poética. Dessa forma, (Bachelard,

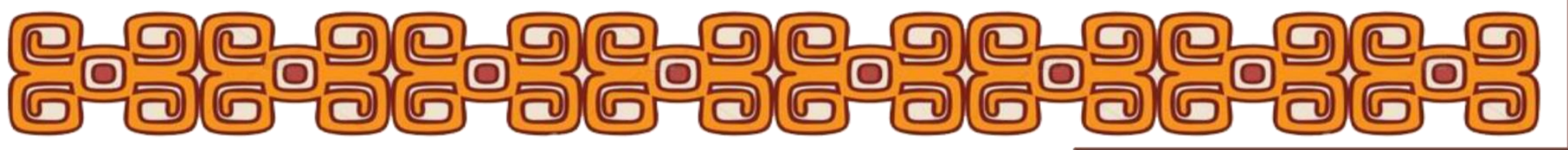




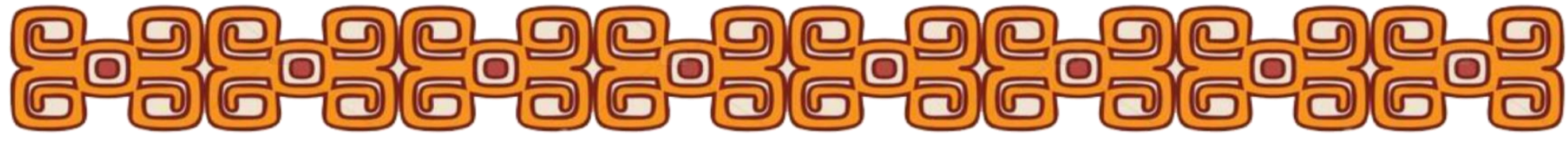

A colisão entre os dois povos legou a história pelos séculos posteriores a imagem de guerreiras nativas, dispostas à ação contra quem quer que seja para fazer prevalecer sua liberdade e soberania. $\mathrm{Na}$ atualidade, parte desta mística centenária está sendo incorporada por mulheres da região amazônica, numa espécie de reavivamento do ancestral protagonismo feminino motivado pela aura ancestral das mitológicas amazonas.

Portanto, é inegável que a maior prova de que o verdadeiro problema a ser enfrentado, antes mesmo de ser social e de ordem da própria essência do ser humano, parte da falta de compreensão do valor integral e inviolável da pessoa da mulher. Assim, com a ascensão das mulheres amazônidas aos postos de liderança, alcançou-se um novo patamar nas relações entre os gêneros, sinalizando para a concretização dos anseios universais por uma sociedade mais justa, em que as oportunidades de desenvolvimento humano sejam iguais para todos. No contexto de reconstrução identitária individual e coletiva colocado em evidência pela nova face do feminismo e da feminilidade.

\section{CONSIDERAÇÕES}

A presente pesquisa trouxe uma análise do pensamento de Edith Stein sobre estudos da fenomenologia da alma humana e o protagonismo feminino. Dessa forma, os estudos sobre Stein oferecem uma grande contribuição para a compreensão do ser humano com a experiência - e a riqueza e a diversidade que emergem dessa - devem constituir uma riqueza pessoal e, sobretudo, uma consciência profunda da "originalidade" e da "igualdade" de cada pessoa. A autora, portanto, ao partir das investigações para a compreensão do que é a pessoa humana, considera a estrutura da pessoa nas dimensões corpóreas, psíquicas e espirituais como elemento útil às pessoas no favorecimento recíproco do reconhecimento do outro.

Espera-se que esta pesquisa tenha ressonância para o mundo acadêmico, assim como contribuiu imensamente para meu crescimento intelectual enquanto pesquisador, mas especialmente, para o crescimento humano e espiritual do pesquisador.

O que se apresenta ao meio acadêmico é fruto de um pensamento reflexivo,

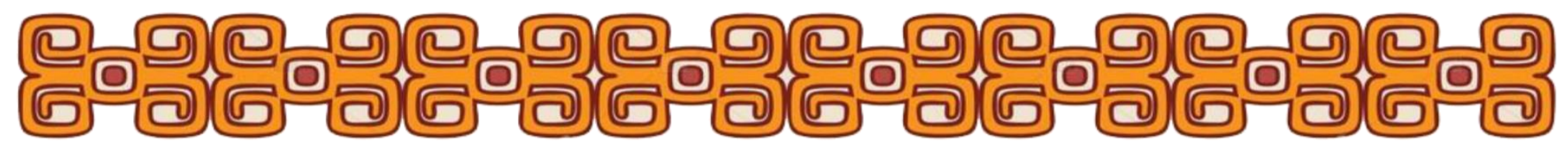




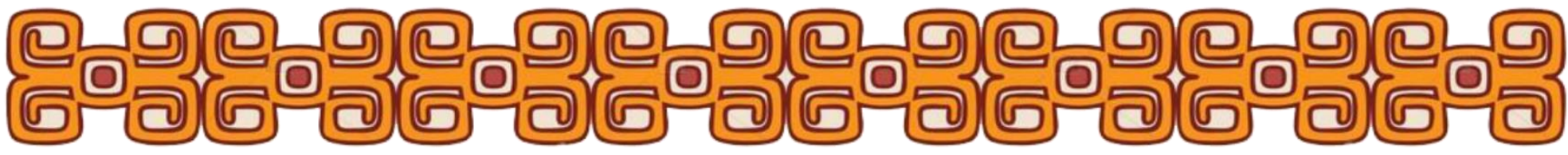

Portanto, as potencialidades existentes em seu ser, uma vez trabalhadas, tornam a mulher competente, capaz de atos jamais vistos, de ações antes impensáveis. E é justamente para isso que Edith Stein empreende uma verdadeira batalha nesta descoberta do ser feminino. Seu maior desejo está em fazer com que a mulher não mais esteja paralisada em si mesma, presa a um pensamento de emancipação, que nada mais é do que a ratificação de uma realidade machista. Em sua análise, conclui: que o centro da alma feminina é a afetividade, justamente por uma busca de amar e ser amada. Sua preocupação volta-se para o aspecto da formação, mas que consiste no que une os indivíduos femininos na espécie feminina.

\section{REFERÊNCIAS}

BACHELARD, Gaston. A Poética do Devaneio. São Paulo: Martins Fontes, 2007.

BEAUVOIR, Simone de. O segundo sexo. A experiência vivida (vol.2).2. ed. São Paulo: Difusão Européia do Livro,1967.

BOAVENTURA, S. S Meneses, M.P Epistemologias do Sul. Coimbra. Almeidina, 2009. FERRAZ, Marcus. Fenomenologia e ontologia em Merleau-Ponty. Campinas: Papirus, 2009. GARCIA, Jacinta Turolo. Edith Stein e a Formação da Pessoa Humana. 2. ed. São Paulo: Edições Loyola, [s.d.].

HUANACUNI, Fernando.Cosmovisión andina: Tierra y territorio - autodeterminación de los pueblos. In.Sariri-Caminante de los Andes, junio 2007 JUNG, E. Animus e Anima. 12a edição, São Paulo: Cultrix, 1999.

MACHADO, Lia Zanota. Perspectiva e confronto: relações de gênero ou patriarcado contemporãneo? Série Antropologia n० 284, UNB, 2000.

MAFFESOLI, Michel. Elogio da Razão Sensível. Petropólis, RJ: Vozes, 1996.

MERLEAU-PONTY, M. A Natureza: curso do Collège de France. São Paulo: Martins, 2006. MORIN, Edgar. Introdução ao pensamento complexo. Porto Alegre: Editora Sulina, 2005. PAREDES, M. RIGOBERTO "Anotaciones Bibliográficas. Las obras de don Horacio H. Urteaga": En "Boletín de la Sociedad Geográfica de La Paz" La Paz-Bolivia. Sep. 1921.

PERROT, Michelle. Os excluídos da História: operários, mulheres e prisioneiros. $2^{\mathrm{a}}$ ed. Rio de Janeiro: Paz e Terra, 1992.

RAGO, Margareth. As Mulheres na Historiografia Brasileira. In: SILVA, Zélia Lopes da (org.). Cultura Histórica em Debate. São Paulo: Editora da Unesp, 1995.

SAFFIOTI, H. I. B. Gênero, patriarcado e violência. São Paulo: Fundação Perseu Abramo, 2004.

SCOTT, Joan. Gênero: uma categoria útil de análise. IN: Educação e Realidade, v. 16, n.2, p. 5-22, Porto alegre, 1990.

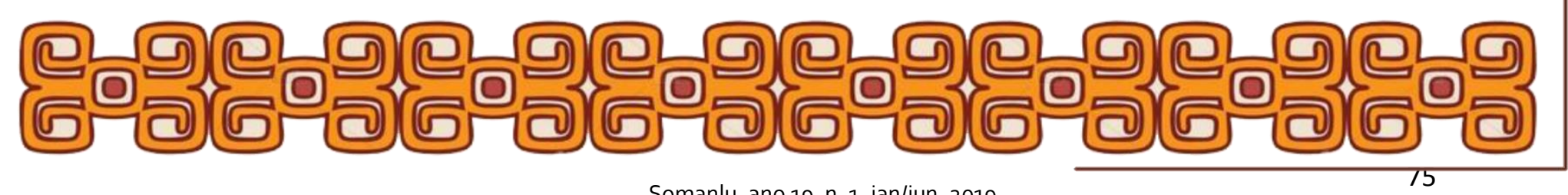




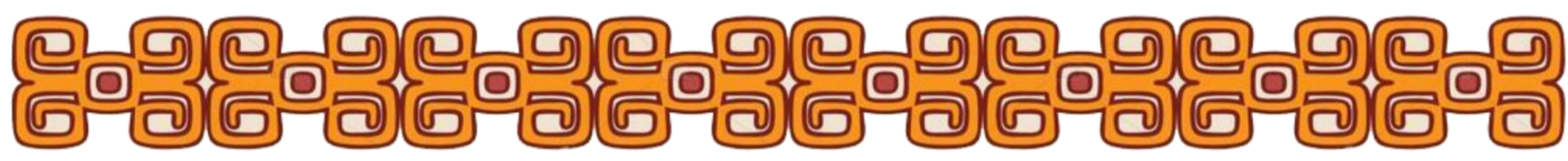

STEIN, Edith. A ciência da cruz: estudos sobre são João da Cruz. São Paulo: Loyola 2004. . A Mulher: Sua missão segundo a natureza e a graça. Tradução de Alfred J.

Keller. Bauru/SP: EDUSC, 1999.

La estructura de la persona humana. Madrid: Biblioteca de Autores Cristianos, 2002.

Na força da cruz. 2. ed. São Paulo: Cidade Nova, 1987.

- Obras Completas, II Escritos Filosóficos: etapa fenomenológica. Madrid:

Monte Carmelo, 2005. Obras Completas, III Escritos Filosóficos etapas de pensamiento Cristiano. Madrid: Monte Carmelo, 2007.

Carmelo, 2003.

Obras Completas, IV Escritos Antropológicos y Pedagógicos, Madrid: Monte

TORRES, Iraildes Caldas.(Org.). Entrelaçamento de gênero na Amazônia. Manaus: Valer, 2015 .

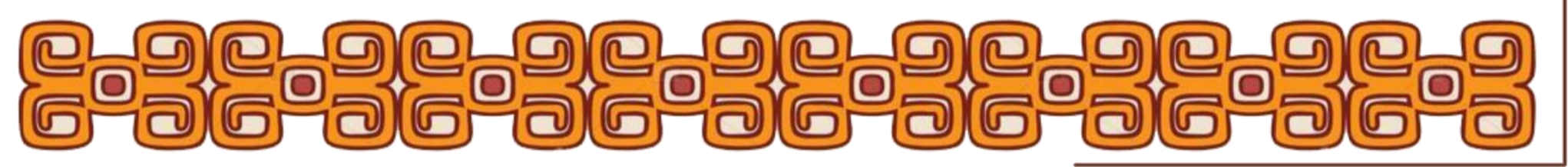

